\title{
Intelligence in Military Missions: Between Theory and Practice
}

\author{
Sebastiaan Rietjens
}

\section{Contents}

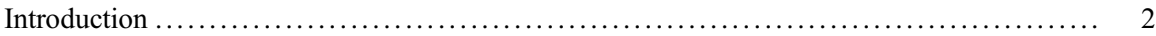

Changing Nature of Intelligence and Schools of Thought $\ldots \ldots \ldots \ldots \ldots \ldots \ldots \ldots \ldots \ldots \ldots, \quad 3$

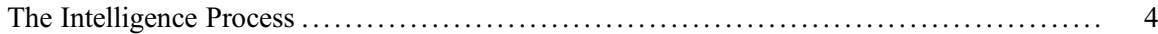

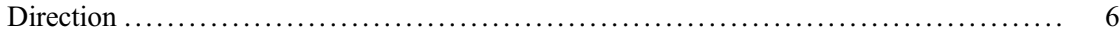

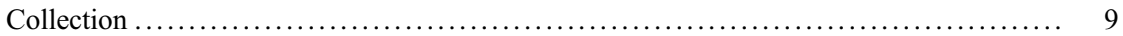

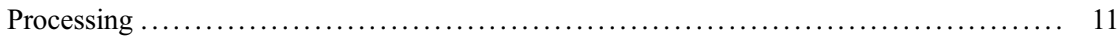

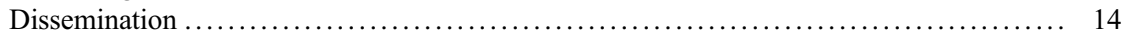

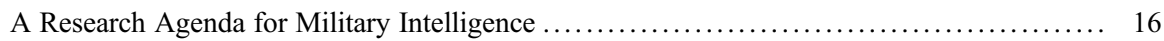

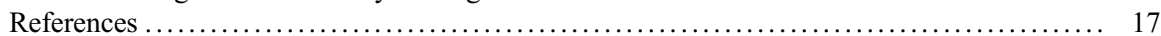

\section{Abstract}

Intelligence is the primary mechanism that military organizations use to generate understanding and its main purpose is to provide information to decision-makers such as commanders that may help illuminate their decision options. This chapter assesses the role of intelligence in military missions, more specifically the counterinsurgency and stabilizations missions that took place in, for example, former Yugoslavia, Iraq, Afghanistan, and Mali.

The chapter starts by addressing the changing and increasingly complex nature of many of the conflicts from the 1990s onwards. It explores how this has influenced the use of intelligence and presents two distinct schools of thought. The first school of thought, referred to as Jominian intelligence, tries to unravel the operational environment in a systematic way and regards the intelligence challenges as a series of problems with definite solutions. The second school of thought, referred to as Clausewitzian intelligence, argues that the goal of intelligence is to assess uncertainty and reach a deliberate judgment.

The main body of the chapter then analyzes the intelligence process and identifies several of the main intelligence issues within military missions. The

S. Rietjens $(\bowtie)$

Netherlands Defence Academy, Breda, The Netherlands 
intelligence process starts with the direction phase in which policy makers, military commanders, or planners state their needs, often referred to as information requirements. Several issues complicate such direction, including (1) the comprehensive focus of many current military missions, (2) their abstract and ambiguous strategic objectives and expectations, and (3) the military's unfamiliarity with the area of operations.

In the second phase of the intelligence process, the necessary information is collected. In addition to consulting their archives and databases, military units often have a plethora of means, both technical and human, available to collect information. Cross-cultural competencies are of crucial importance, in particular, during the collection phase.

The third phase of the intelligence process, labeled processing, turns raw data into intelligence. During the processing phase, the data are analyzed in order to gain understanding or insight. This exceeds the registration of events, but includes understanding the meaning of these events as well as their importance.

The fourth and final phase is dissemination of intelligence. Here, the relationship between the producers and consumers of intelligence during military missions is explored. This includes the reasons why consumers sometimes do not fully accept the intelligence they receive.

The chapter concludes with an agenda for research on military intelligence. It calls, for example, for a more eclectic author base; multidisciplinary as well as comparative research; increased attention to oversight, ethics, and open source intelligence; and more emphasis on intelligence within the navy, special forces, and constabulary forces.

\section{Keywords}

Intelligence $\cdot$ Military $\cdot$ Direction $\cdot$ Collection $\cdot$ Processing $\cdot$ Dissemination

\section{Introduction}

Operations in Afghanistan and Iraq since 2001 have reminded us of the truism already offered by Sun Tzu and Clausewitz that military success requires deep understanding of the nature of the war, and the broader strategic and operational environment. As the UK Joint Doctrine Publication 04 - titled Understanding argues, "understanding provides the context for the decision-making process which informs the application of national power. The purpose of understanding is to equip decision-makers at all levels with the insight and foresight required to make effective decisions as well as manage the associated risks and second and subsequent order effects" (UK MOD 2010, pp. 1-1). Many academic studies that were published as a reflection of the challenges encountered during the counterinsurgency and stabilizations missions reflect this awareness and stress the importance of understanding (e.g., Gentry 2010; Shultz 2018). 
Intelligence is the primary mechanism that military organizations use to generate understanding and its main purpose is to provide information to decision-makers such as commanders that may help illuminate their decision options (Johnson 2010). Following Lowenthal (2017, p. 11) intelligence is defined in this chapter as "the process by which specific types of information important to military organizations are requested, collected, analyzed and provided to commanders and decision makers at all levels, the product of that process, and the safeguarding of these processes and this information by counterintelligence activities and the carrying out of operations as requested by lawful authorities."

This chapter assesses the role of intelligence in military missions, more specifically the counterinsurgency and stabilizations missions that took place in, for example, former Yugoslavia, Iraq, Afghanistan, and Mali. To do so the next section presents the changing nature of intelligence and the main schools of thought on intelligence. Section "The Intelligence Process" introduces the intelligence cycle and, by making use of this concept, identifies several of the main intelligence issues within military missions. Section "A Research Agenda for Military Intelligence" concludes the chapter. It outlines the academic study on intelligence in military organizations and identifies several main research gaps.

\section{Changing Nature of Intelligence and Schools of Thought}

From the 1990s onwards, the types of conflicts and therefore the operational environments in which military missions took place have significantly changed. Mary Kaldor (2012) refers to these conflicts as "new wars" that are characterized by violence of different combinations of state as well as nonstate actors, large-scale displacement of people, fragile or failing economic, political, and social institutions, random and systematic violence against noncombatants, and widespread lawlessness. Whereas conflicts before the 1990s often showed a clear demarcation between war, organized crime, and mass atrocity, this is far less so in new wars. Examples of these new wars are Syria, Afghanistan, Iraq, and Mali.

The changing nature of conflicts has also influenced the use of intelligence. During conventional inter-state conflicts intelligence was often regarded as a puzzle that could be solved (Treverton 2007). For example, during the Cold War American intelligence services focused on many of these puzzles such as: How many longdistance missiles did the Soviet Union have? Where are they positioned? What is their reach? And how accurate are they? Answering these questions enabled the American intelligence services to solve the puzzle and assess the Soviet threat.

Compared to the inter-state conflicts, most recent conflicts are far more complex. As a result of this, challenges with which the armed forces are confronted can no longer be regarded as puzzles. In an effort to elucidate the current challenges, Treverton (2007) describes them as complex mysteries. These challenges are ambiguous and fuzzy and lack proven knowledge and fixed standards to achieve the intended objectives. This resembles the definition of wicked problems (Rittel and Webber 1973). These wicked problems are not unique to military operations. Other 
examples of such problems are the global financial crisis that struck the world as of 2008, global warming, acts of terrorism, and refugee streams.

In an effort to visualize the problems in Afghanistan, general Stanley McCrystal and his staff designed the diagram that is depicted in Fig. 1. This example illustrates the complex nature of current conflicts. Or as McChrystal remarked: "When we understand that slide, we'll have won the war" (The Guardian 2010).

Within the intelligence literature, there are basically two distinct schools of thought how to deal with such levels of complexity. The first school is often referred to as Jominian intelligence, after the French strategist Antonie-Henri Baron de Jomini. This school of thought tries to unravel the operational environment in a systematic way and regards the intelligence challenges as a series of problems with definite solutions. Much in line with the diagram that McChrystal made on Afghanistan. This school often refers to intelligence as a science (see, e.g., Marrin 2012). Critics of this school point at the impossibility of incorporating all the relevant elements of the environment in an analysis (Galster 2015). And if one would succeed in this quest, this approach will result in a severe simplification of reality. This will then lead to solutions that do not meet the problems for which they are intended.

The second school of thought acknowledges these problems (Agrell and Treverton 2015). This school is named after the Prussian general and military theorist Carl von Clausewitz, who argued in his well-known publication On War that "war is in the realm of uncertainty; three quarters of the factors on which action in war is based are wrapped in a fog of greater or lesser uncertainty" (Von Clausewitz 1984, p. 101). As a result, he continued: "many intelligence reports in war are contradictory; even more are false, and most are uncertain ... In short, most intelligence is false" (Von Clausewitz 1984, p. 117). The Clausewitzian school of thought thus argues that the goal of intelligence is to assess uncertainty and reach a deliberate judgment (Galster 2015). This school therefore regards intelligence as an art instead of a science.

Table 1 summarizes the main differences between these two schools of thought.

Based on this background the next section zooms in on the process by which military organizations obtain intelligence during the recent stabilization and counter insurgency missions.

\section{The Intelligence Process}

In general terms, the process by which a knowledge requirement is transformed into a policy advice is often described as the intelligence cycle. There are several varieties of this cycle depending on the number of phases one discerns. A further discussion on the differences and similarities of these varieties is outside the scope of this chapter. For this see, for example, Omand (2014). A well-known and often used version of the intelligence cycle is that of the British Army (see Fig. 2). This cycle discerns four main phases in the intelligence process: direction, collection, processing, and dissemination. The following sections address each of these phases in more detail and identify the main intelligence issues within military operations. 


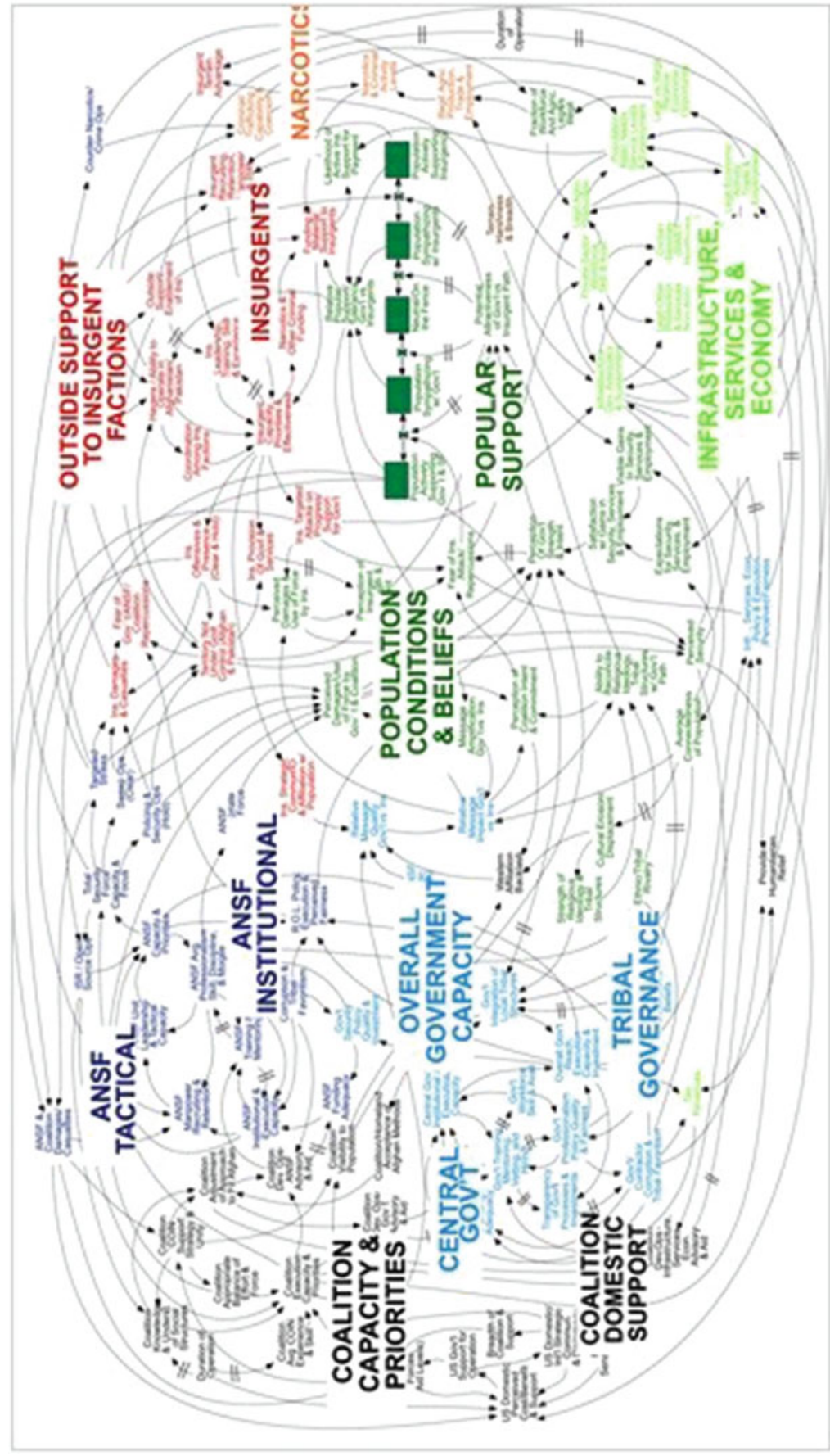

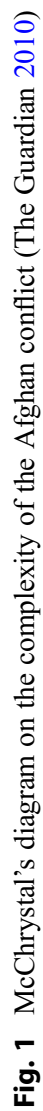


Table 1 Jominian versus Clausewitzian intelligence (Agrell and Treverton 2015, p. 37)

\begin{tabular}{l|l}
\hline Jominian intelligence & Clausewitzian intelligence \\
\hline Goal is to eliminate uncertainty & Goal is to assess uncertainty \\
\hline There is a "right" answer & "Fog of war" is inescapable \\
\hline $\begin{array}{l}\text { More information and better concepts } \\
\text { narrow uncertainty }\end{array}$ & $\begin{array}{l}\text { Single-point high-probability predictions both } \\
\text { unhelpful and inaccurate }\end{array}$ \\
\hline $\begin{array}{l}\text { Large uncertainty indicates shortcomings } \\
\text { to analysis }\end{array}$ & $\begin{array}{l}\text { Better analysis may identify more possible } \\
\text { outcomes }\end{array}$ \\
\hline
\end{tabular}

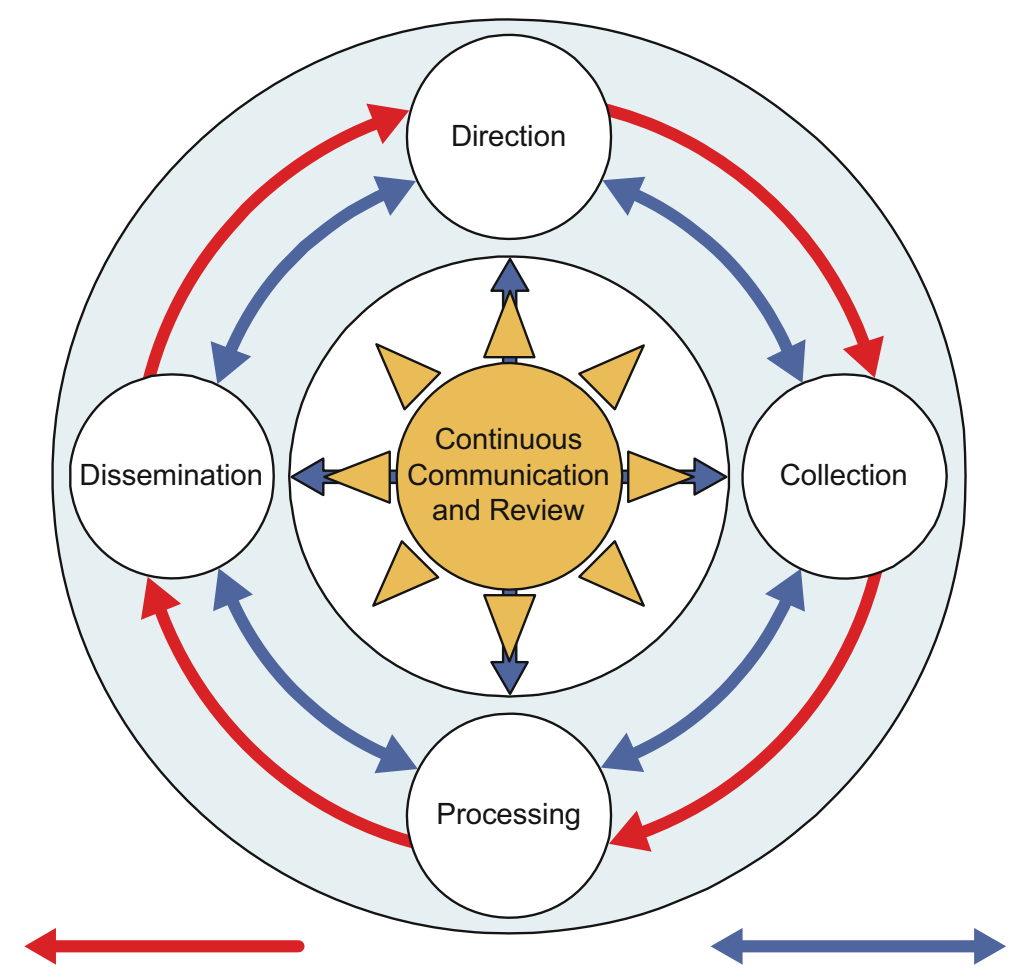

Basic Intelligence Cycle

Feedback and Dialogue

Fig. 2 Intelligence cycle (UK Ministry of Defence 2011)

Empirical evidence from operations in Afghanistan, Mali, Syria, and Iraq is used to illustrate these main issues.

\section{Direction}

The first phase of the model is labeled direction. Here, policy makers, military commanders, or planners state their needs, often referred to as information 
requirements. The information requirements can broadly be divided in three categories: information that contributes to (1) general situation awareness, (2) an ongoing operation, or (3) a future operation. All the separate intelligence requirements are then organized into a collection plan. Critics of the intelligence cycle (e.g., Hulnick 2006; Phythian 2014) argue that an initial knowledge requirement on the part of politicians, commanders, or military planners as the starting point of the intelligence cycle is debatable. In fact, often it is intelligence personnel that tell their masters what they think they should know more about. But even for them it is sometimes difficult to define adequate information requirements. For example, in case of socalled unknown unknowns (see, e.g., Rumsfeld 2002), it becomes by definition impossible to define information requirements.

Traditionally, information requirements in military missions have primarily emphasized the enemy (e.g., strength and disposition of enemy units, enemy morale), the weather conditions (e.g., weather forecast, conditions of surf and tide on the beaches), and the terrain (e.g., condition of roads, location of mine fields) (Glass and Davidson 1952).

Most recent military missions, however, take place in increasingly complex environments (see also section "Changing Nature of Intelligence and Schools of Thought"). Typically, many of these missions are not solely kinetic, but multidimensional in nature, having military, political, economic, and judicial aims (Koops et al. 2015, p. 613). As such, intelligence on merely security-related aspects does not suffice. Rather, military organizations need understanding on a broad range of issues, including but not limited to governance, socio-economic, and criminal challenges (Bruls and Dorn 2014). For example, NATO and Coalition of the Willing alliances during their missions in Afghanistan and Iraq learned that populationcentric intelligence was essential to progress (e.g., Flynn et al. 2010; Kitzen 2012; Perugini 2008). As Flynn et al. stress:

The lesson of the last decade is that failing to understand the human dimension of conflict is too costly in lives, resources, and political will ... a new [intelligence] concept should seek to explain how populations understand their reality, why they choose either to support or resist their governments, how they organize themselves socially and politically, and why and how their beliefs transform over time.

To address such comprehensive information requirements, NATO introduced the concept of PMESII. This implies that intelligence has to be obtained on different domains: Political, Military, Economic, Social, Infrastructure, and Information. A striking example within the economic domain is the production of poppy in Afghanistan. Poppy is the raw material for heroin and opium and around the year 2000, Afghanistan was responsible for approximately $90 \%$ of its production worldwide. ISAF forces soon realized that addressing the poppy production was essential in order to stabilize Afghanistan. Military troops thus got involved in destroying poppy fields as well as disrupting the drugs trade (Donkersloot et al. 2011). To do this, the troops needed to understand the complex drugs network and therefore gathered information on, for example, drug labs, traffickers, and drugs-related corruption. 
Incorporating all PMESII domains in the intelligence gathering process is very much in line with the Jominian school of thought (see section "Changing Nature of Intelligence and Schools of Thought"). Although it might seem self-evident, this approach has severe disadvantages. Basically, military troops run the risk of developing a collection plan that includes many different information requirements and is therefore very broad in scope and lacks focus. Moreover, mapping all these different aspects consumes a great amount of time, energy, and financial resources. An intelligence officer of the MINUSMA troops in Mali formulated this as follows:

\begin{abstract}
With the best of intentions ASIFU [i.e. the main intelligence unit within the MINUSMA force] created an intelligence collection plan of 75 pages that was not workable in any way. In their plan they deconstructed the entire Malian society along the lines of each of the PMESII [Political, Military, Economic, Social, Infrastructure and Information] factors and presented that as their information need, very much in line with the traditional intelligence officer sending a request saying "give me everything about...." (Rietjens and de Waard 2017, p. 540).
\end{abstract}

Directing the intelligence process is further complicated by the abstract and ambiguous strategic objectives and expectations that are inherent to many military missions. Looking at the different countries that contribute troops to a multinational military mission, one discerns a plethora of national objectives. In some cases, countries clearly formulate and communicate their objectives, while in other cases they do not express their objectives openly. The contribution of NATO countries in Afghanistan illustrates this well. Apart from the overarching mission to contribute to a safe and secure Afghanistan, countries aimed at countering terrorism, increasing their political influence by contributing troops (e.g., to be invited to the G20), sharing the burden of the international efforts or to avoid budget cuts in their home countries by deploying troops (Farrell et al. 2014). Each of these objectives led to different information requirements. It turned out difficult to align all the information requirements, in particular when countries did not openly express their objectives, which obscured the direction of the intelligence process.

A last issue complicating the direction of the intelligence process is the military's unfamiliarity with the area of operations to which they are deployed. Most recent military missions take place in far-away countries that show little resemblance with the home countries of western soldiers. While most military agree that it is important to gain in-depth understanding of, for example, the root causes of a conflict as well as the political and social structures of a host nation, in practice they find it difficult to do so. There are at least three main reasons for this. First, predeployment training programs often emphasize the military skills and drills and pay only little attention to knowledge about the area of operation. Second, most military spend only a relatively short period in the mission area. Tours of 4 to 6 months are increasingly common and an often-heard complain is that just when people come to grips with the situation, they have to leave the mission area. This is devastating for the effectiveness of intelligence in military units. Third, when a political decision is made to send troops to a mission area, the military often has little time to prepare for their mission and gain upfront understanding of the environment in which they will operate. And as 
soon as the troops are deployed, they are overwhelmed with day-to-day challenges and find it difficult to see the whole picture. As a result, they are often not able to adequately formulate the information requirements.

\section{Collection}

In the second phase of the intelligence cycle, the necessary information is collected. In many cases, military commanders have a plethora of means available to collect information. Before tasking resources to collect the required information, the first step is often to consult the archives and databases to which the unit has access. In military operations, such databases include, for instance, information on key leaders, armed groups, settlements, and criminal activities. An example of a database that was widely used in Afghanistan was the so-called Afghanistan Country Stability Picture (ACSP) (Davids et al. 2011). This database contained information on approximately 85,000 reconstruction and development projects from all over the country. For each project, the database included several characteristics such as start date, costs, location, and under what pillar of the Afghanistan National Development Strategy the project was grouped (e.g., governance, infrastructure, or health and nutrition).

In practice using these databases comes with many challenges. There are many examples of databases that were largely unstructured or those that missed crucial data. And although there are many tools and software programs available to set up and manage databases, frequently they were developed and maintained by individual soldiers. This greatly hampered the continuity and sustainability when these soldiers left the mission area. Also, a lack of interoperability between different databases hampered military units in retrieving information (Rietjens and Baudet 2017).

When the required information is not available in the databases, military commanders have several different means available to collect the information. First of all, and following the US Army training slogan, every soldier is a sensor. "The slogan reflects the fact that every member of a deployed formation has a responsibility to collect intelligence as part of his or her duties. This includes reports from liaison officers, reports on official meetings and reports from routine duties (patrols, checkpoints, etc.)" (UK MOD 2011, pp. 3-14).

In addition to using the individual soldiers as sensors, military commanders can task one or multiple collection resources. Within intelligence studies, the following classification of the intelligence collection disciplines, often referred to as the INTs, is generally accepted:

- Geospatial intelligence (Geoint) refers to "the exploitation and analysis of imagery and geospatial information to describe, assess and visually depict physical features and geographically referenced activities on the earth" (Lowenthal and Clark 2016, p. 111). Examples of Geoint include satellite photos or video images from unmanned aerial vehicles (UAVs). 
- Signals intelligence (Sigint) is intelligence-gathering by the interception of signals. These signals can originate from communications between people such as telephone and radio communications or from electronic emission devices not directly used in communication such as radar (Lowenthal and Clark 2016).

- Measurement and signature Intelligence (Masint) is "technically-derived intelligence that enables detection, location, tracking, identification and description of unique characteristics of fixed and dynamic target sources. Masint embodies a set of sub-disciplines that operate across the electromagnetic, acoustic and seismic spectrums, and material sciences. Masint capabilities include radar, laser, optical, infrared, acoustic, nuclear radiation, radio frequency, spectro-radiometric and seismic sensing systems as well as gas, liquid, and solid materials sampling and analysis" (Lowenthal and Clark 2016, p. 160).

- Human intelligence (Humint) refers to the collection of intelligence by human sources. Typical humint activities consist of interrogations (for an overview see Hassner 2019) and conversations with persons that have access to information. Humint is often associated with espionage or the clandestine acquisition of secrets by a human source (Lowenthal and Clark 2016). However, humint also includes the overt collection of intelligence such as by engaging with key leaders in a mission area.

- Open source intelligence (Osint) is the information that is publicly available to anyone through legal means. Osint includes a wide variety of sources including media (e.g., newspapers, magazines, television), public data (government reports, press conferences), and academic sources (e.g., conferences, scientific papers) (Lowenthal 2017).

In selecting and tasking the resources, the commander's intelligence staff generally considers several factors. These include security (i.e., sources must be adequately protected), capability (i.e., the resource or unit must possess the appropriate sensor), weather and balance of tasking (i.e., an even distribution in workload between the different resources and units) (see, e.g., UK MOD 2011, pp. 3-15).

To illustrate this, one might think of the use of geospatial intelligence. A military commander could use different means to get such intelligence. These include satellites, helicopters, airplanes, or unmanned aerial vehicles. Each of these resources has different characteristics. In many of the recent stabilization operations, it was necessary to gather information on the daily pattern of life. That requires flying the same route at the same time daily, simply hovering over the area, and counting, for example, the amount of smoking chimneys. This makes unmanned aerial vehicles better equipped to the task as compared to the other collection resources as they can stay in the air for many hours, are easy to control, and are unlikely to be detected.

For many of the collection (and processing) activities during stabilization and counter insurgency missions, cross-cultural competencies are of crucial importance. These competencies are broadly defined as "the ability to quickly and accurately comprehend, then appropriately and effectively engage individuals from distinct cultural backgrounds to achieve the desired effect. (1) Despite not having an in-depth 
knowledge of the other culture, and (2) Even though fundamental aspects of the other culture may contradict one's own taken-for-granted assumptions/deeply-held beliefs" (Selmeski 2007, p. 12).

Abbe and Halpin (2009) identify three main components that are necessary to acquire cross-cultural competence and therefore to effectively work in a foreign culture. The first component is cultural knowledge. Such knowledge begins with an awareness of one's own culture and includes an understanding of culture and cultural differences through schemata or frameworks. In many cases, military units were not sufficiently aware of the complexity of the conflict, the history of the area they operated in, as well as the ethnic sensitivities (e.g., Kitzen 2012). This negatively influenced their effectiveness, as they were not fully able to unravel the dynamics of the environment and address the information requirements they were tasked with. In response to this, many troop contributing countries started to embed cultural knowledge in the predeployment training of their troops. But this was often not sufficient.

The second component of cross-cultural competencies is affect and includes attitudes toward other cultures and the motivation to learn about and engage with them. In this regard openness and empathy are of particular importance. The stereotypical images of soldiers wearing mirrored sunglasses when talking to local Afghans is a clear example of not having affect.

The third component of cross-cultural competencies is skills. These "encompass the ability to regulate one's own reactions in a cross-cultural setting, interpersonal skills, and the flexibility to assume the perspective of someone from a different culture" (Abbe and Halpin 2009, p. 24). As part of the latter, linguistic skills often play an important role in the collection process. In many cases, the authorities and population in the area of operation communicate in a language that the international troops do not master. In the case of Afghanistan, this includes Farsi, Pashto, or Dari, while in the Sahel Arab, Tamashek and dozens of other languages are spoken. Language inadequacy greatly hampers the collection and processing of literal intelligence through osint, humint, or sigint. To address this issue, military units widely use local as well as international interpreters. While they are able to compensate for part of the military's linguistic skills, military units are often unable to effectively deploying these interpreters (Van Dijk and Soeters 2008).

\section{Processing}

The third phase of the intelligence cycle is labeled processing. Here, raw data are turned into intelligence. It is particularly during this phase that the changing character of the data is important. The most prominent data characteristics are often referred to as the 4 Vs of Volume, Veracity, Velocity, and Variety. Figure 3 illustrates these characteristics for military missions (Atwood 2015).

The V of volume (top right quadrant) refers to the continuously increasing amount of the data that needs to be processed. The technical intelligence collection disciplines - geospatial, signals, measurement, and signatures - have contributed most to this due to the highly sophisticated sensors that are employed on an array of 

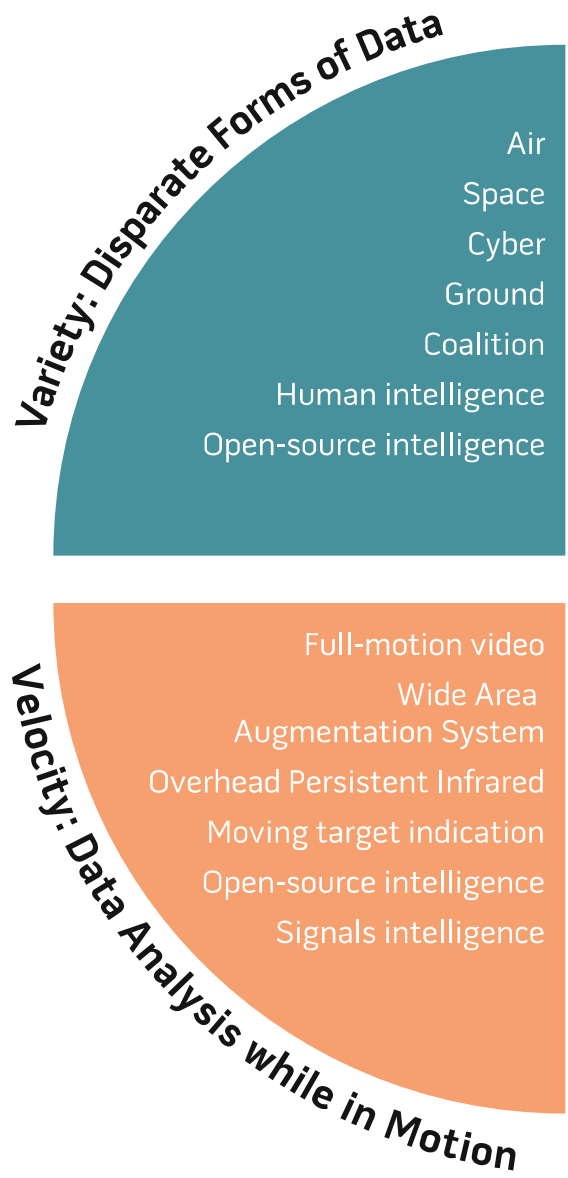
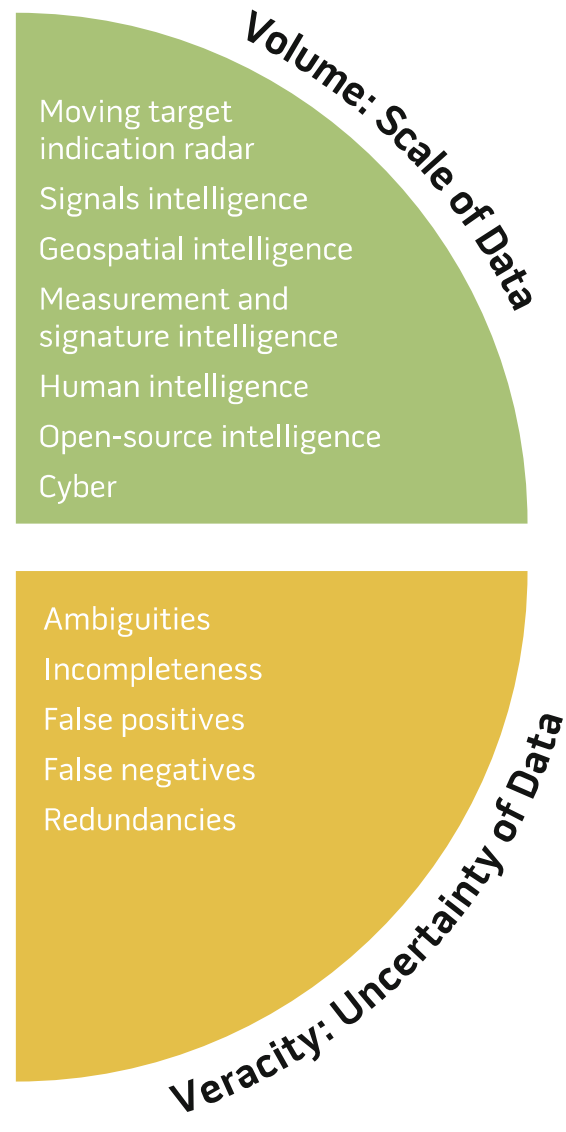

Fig. 3 The four Vs (Atwood 2015)

platforms (Shultz 2018). The introduction of new technological platforms such as the F35, the MQ-9 Reaper, or the advancement of the soldier modernization program will only further increase the volume of data. This poses great challenges to the collecting and processing capacities of the organizations involved.

The V of veracity (lower right quadrant) refers to the uncertainty of the data. Data is often ambiguous, incomplete, or incorrect. Establishing the trustworthiness of the source and the data itself are therefore essential in this phase.

With regard to the third $\mathrm{V}$ of velocity (lower left quadrant), one observes an increase in data that is available in real-time such as videos made by unmanned aerial vehicles or social media feeds.

The fourth and final $\mathrm{V}$ refers to variety. Military have to cope with multiple data formats with structured as well as and unstructured data from, for example, text, image, multimedia content, audio, video, sensor data, or noise. 
During the processing phase, the data are analyzed in order to gain understanding or insight. This exceeds the registration of events, but includes understanding the meaning of these events as well as their importance. For example, during stabilization missions, it might not be sufficient to know the disposition of the warring factions. To effectively operate, it might be crucial for military units to understand why these factions are in conflict, what allies they have and how the conflict impacts the local population.

Due to the increasing complexity of recent military missions, many intelligence staffs have deployed various different types of analysts. Examples include the traditional military analysts that emphasize the traditional information requirements that we have seen earlier (i.e., enemy, weather, terrain). Additionally, human terrain analysts are deployed to focus on the cultural, political, and economic factors of the local actors, whereas geospatial analysts are responsible for analyzing imagery that is developed by photographic and electronic means.

Despite these functional analytical specializations, gaining understanding is challenging and runs the risk of misinterpretations. In this respect, one distinguishes between an intelligence error and an intelligence failure. While intelligence errors are "factual inaccuracies in analysis resulting from poor or missing data... intelligence failures are systemic organizational surprise resulting from incorrect, missing, discarded, or inadequate hypotheses" (Johnston 2005, p. 6).

Intelligence errors frequently occur in the intelligence process. Paying extreme care to the validation of the data can help address this as well as collecting the information that is missing.

To reduce the chance for intelligence failures, the intelligence community has developed many different analytical techniques (Odom 2008). Heuer and Pherson (2011) provide an extensive overview of over 50 of them, which have become known as structured analytic techniques. These techniques include "Analysis of Competing Hypotheses," "Delphi Method," and "Scenario Analysis." Analysts within military units apply these techniques to different degrees.

While most of the techniques work with qualitative data, Atwood (2015, p. 26) argues that:

The increase in sensors and resulting vast amounts of disparate data coupled with the increasing capabilities of IT systems to handle the deluge are transforming intelligence analysis. The traditional process of stitching together sparse data to derive conclusions is now evolving to a process of extracting conclusions from aggregation and distillation of big data.

There are several techniques that can help analysts understand, identify, and visually display key elements in these vast amounts of data such as key individuals, social relationships, patterns, and trends. Social network analysis (see, e.g., Waltz 2014) is a prominent example of such a technique. However, social network analysis as well as other similar techniques are highly mathematical. Since most analysts in military intelligence agencies or staffs do not have a computer science or mathematical background, they find these techniques difficult to adopt. 
Likewise, social network analysis is ineffective without the specific domain knowledge that most analysts bring along. The main challenge is therefore to effectively combine quantitative and qualitative methods and techniques. Processing and analysis thus increasingly become a multidisciplinary challenge in which personnel, procedures, and information systems with different backgrounds have to be integrated or at least understand each other (see, e.g., Bang 2016).

\section{Dissemination}

As General Alfred Gray, former commandant of the US Marine Corps, already stated: "Intelligence without communication is irrelevant" (Otte 2015, p. 41). To prevent this from happening, the final phase of the intelligence cycle, that is labeled dissemination, addresses the communication of intelligence to its consumers. The scholarly literature on the relation between the producer and consumer of intelligence is considerable (see, e.g., Marrin 2017; Lowenthal 2010), but the topic has been less studied during war and conflict (Gentry 2019).

In general, one observes that intelligence consumers such as decision-makers and military commanders have tight agendas and rarely have the time to read full reports. Effectively communicating the intelligence products is therefore extremely important. To do this, intelligence doctrine publications prescribe that a product needs to capture the essence of what is known or, to be more precise, thought to be known about a certain threat or opportunity. A product needs to be timely and actionable, that is, the assessment must be presented before the threat materializes and it must contain information that will help the leadership make up their mind about how to deal with it. At times these principles - timely and actionable - might get into conflict. Therefore, in urgent cases when time is at premium, "processing of information may not be possible and dissemination should be as quickly as possible, with the caveat that it is unprocessed and may not be reliable" (UK MOD 2011). Security is another main issue in disseminating an intelligence product. The classification of the intelligence product should reflect its content. Over-classification might cause delays in handling and transmission, while under-classification runs the risk to needlessly reveal the source of information.

There are several formats through which the assessments resulting from the processing phase are being communicated to the consumers. This includes a verbal, written, interactive, or graphic format. Overall the intelligence products should enable a commander to (US Army 2019):

- Plan operations and employ maneuver forces effectively

- Recognize potential courses of action

- Conduct mission preparation

- Employ effective tactics, techniques, and procedures

- Take appropriate security measures

- Focus information collection

- Conduct effective targeting 
There are, however, many instances that consumers do not accept the intelligence they receive. This was already observed in 1966 when Sherman Kent, a foundational figure in the development of American intelligence analysis, stressed that "no matter how right we are and how convincing ... (policymakers) will upon occasion disregard the thrust of our findings" (Steury 1994, p. 34).

In his research on the relationship between intelligence producers and consumers, Wolfberg (2017) outlines several reasons why military commanders and decisionmakers reject or distort intelligence. Cognitive biases - systematic errors in thinking that affect the decisions people make - play a central role in this process. There are many different cognitive biases. Wolfberg (2017) specifically points at one of them: the confirmation trap bias. This bias implies that one tends to look for confirmatory data to support one's own beliefs when making a decision (Bazerman 2002). As a result, contradictory data are easily rejected. In addition, Wolfberg $(2017$, p. 461) argues that decision-makers and commanders "need confidence in order to shepherd their interests forward but intelligence can be too complicated and ambiguous, and therefore be rejected."

At the level of national security, Marrin (2017) has identified several other reasons why consumers do not fully accept intelligence. These seem to be applicable to military commanders as well and include (1) consumers have their own information channels that are sometimes more up-to-date and accurate than the intelligence provided by the analyst, (2) intelligence analysis can increase uncertainty and complicates policy-making, and (3) consumers might bring more knowledge and experience with them than the intelligence analysts do, which might lead to a different assessment. But as the previous sections have indicated, intelligence products might also be misleading and contain wrong analyses and conclusions. Most consumers are aware of this, which leads them to handle intelligence products with an amount of skepticism.

Finally, when the commander does accept the assessment of the intelligence staff, it is important that there is an effective follow-up. This is often referred to as intelligence-driven operations (Norheim-Martinsen and Ravndal 2011) and means that operations are "driven in timing and objectives by intelligence, including operations to gain intelligence" (Dorn 2009, p. 806). Apart from a well-functioning intelligence process, the realization of such operations depends on the means that military commanders have. Although this might be obvious, commanders have scarce resources such as limited number of troops, inadequate counter IED protection measures, or limited transportation means. Such scarcity might restrict the commanders' ability to carry out certain operations that are driven by intelligence assessments.

This completes the intelligence process. The next and last section will now focus on the academic research that is done on intelligence in military organizations and will identify several research gaps that might be a starting point for future studies. 


\section{A Research Agenda for Military Intelligence}

Although many practitioners, military and civilian alike, have emphasized the need for adequate intelligence in military organizations, only limited scholarly attention has been paid to the topic. As US professor of strategy and co-founder of the journal Intelligence and National Security (INS) Michael Handel (1990, p. 74) states "the most exhaustive military histories scarcely discuss the weighty contribution of intelligence activities." The extensive military campaigns in, for example, former Yugoslavia, Iraq, and Afghanistan, do not seem to have changed this picture. In an overview of intelligence studies, Johnson $(2014$, p. 17) calculated that only $1 \%$ of all publications in the journal INS between 2006 and 2011 addressed military intelligence. In an effort to understand this lack of attention, Johnson argues that most scholars have emphasized intelligence at a strategic level and studied, for example, the role of intelligence in national decision councils. However, meanwhile governments spend much funding on intelligence in support to military operations to meet the information needs of troops at the tactical and operational levels. And whereas "journalists have become more adept at 'embedding' themselves into combat units for reporting on foreign conflicts; scholars have yet to adopt this methodology, which would provide first-hand observations of intelligence-at-work at the tactical level. Nor have scholars conducted many interviews with returned combatants to probe their intelligence experiences in the field" (Johnson 2014, p. 17).

To provide insight in the body of knowledge on intelligence in military organizations, Rietjens (2020) has carried out an extensive literature review of what has been published on this topic in academic and professional journals throughout the last 10 years. Below, some of the main findings are addressed.

First, the authors that study intelligence within military organizations show great uniformity. The great majority of them originate from the United States and United Kingdom; they are almost all male; most of them have a historical background or are military or intelligence professional; and most of the authors are civilian. Following Van Puyvelde and Curtis (2016, p. 1048) "a more eclectic author base, representing a host of cognitive styles and experiences, can enrich and deepen our understanding of intelligence organizations, processes and cultures."

Second, the timeframe and conflicts on which the papers focus show a diverse picture. Much attention has been paid to the recent conflicts in Afghanistan and Iraq as well as to both World Wars. The period 1990-2001 is however highly underresearched. Considering the intense conflicts that occurred during the last decade of the twentieth century and the archives that slowly open up, there seem to be many opportunities to fill this gap the coming years.

Third, many of the publications emphasize collection, intelligence adaptation and reform, the nexus between intelligence and policy or command, intelligence cooperation, and analysis. Some topics, most notably oversight and ethics have, however, received only limited attention. Since military organizations often have wide-ranging mandates and are difficult to oversee, in particular during expeditionary operations, it is very important to pay closer scrutiny to both topics. And although collection as a whole attracted much attention, open source collection was not a popular topic. Since 
this is a rapidly changing field, it is important that scholars step up their effort to study the role of open source intelligence in military organizations (see, e.g., Williams and Blum 2018).

Fourth, corresponding to the country of origin of the authors, the military organizations of the United States and the United Kingdom are by far the most popular research objects. As Richard Valcourt explains "scholars of intelligence benefit from knowledge of the services of a range of countries, compelling them to expand their horizons in terms of the types and range of issues they study. Failure to do so leads to severe gaps in understanding the true nature of the global intelligence community and its practitioners" (Van Puyvelde and Curtis 2016, p. 1041). Ideally, a wider scope should also lead to more comparative studies focusing on the similarities and differences between military organizations (Rietjens 2019). In so doing, Ruffa and Soeters (2014) provide methodological guidance on how to do structured comparative research using different national military operational styles. This could serve as an example for comparing intelligence within different military organizations.

Fifth, many of the publications are descriptive in nature and have ample theoretical foundation. This offers many opportunities to study the topic making use of the body of knowledge from other academic disciplines. Examples of such disciplines include interorganizational cooperation, information management, sensemaking, and complexity theory. Coulthart et al. (2019) offer great examples and inspiration for applying such multidisciplinary approaches to the intelligence studies domain.

Finally, the publications tend to address one specific service. While the air force and the army are studied intensively, other services receive less scholarly attention. There is thus great potential in studying cases of naval intelligence as well as those of the special and constabulary forces.

All in all, the insights of this review and the future pathways it identified should contribute to a greater and more conscious reflexivity of intelligence in military organizations and help to prepare for a turbulent and uncertain future. But as the much-acclaimed military historian John Keegan (2003, p. 349) puts it in perspective "foreknowledge is no protection against disaster ... real-time intelligence is never enough. Only force finally counts."

\section{References}

Abbe, A., \& Halpin, S. M. (2009). The cultural imperative for professional military education and leader development. Parameters, 39, 20-31. Winter 2009-2010.

Agrell, W., \& Treverton, G. T. (2015). National intelligence and science: Beyond the great divide in analysis and policy. Oxford: Oxford University Press.

Atwood, C. P. (2015). Activity-based intelligence: Revolutionizing military intelligence analysis. Joint Forces Quarterly, 77(2), 24-33.

Bang, M. (2016). Pitfalls in military quantitative intelligence analysis: Incident reporting in a low intensity conflict. Intelligence and National Security, 31(1), 49-73.

Bazerman, M. H. (2002). Judgment in managerial decision making (5th ed.). New York: Wiley. 
Bruls, F., \& Dorn, A. W. (2014). Human security intelligence: Towards a comprehensive understanding of complex emergencies. In C. Hobbs, M. Moran, \& D. Salisbury (Eds.), Open source intelligence in the twenty first century: New approaches and opportunities (pp. 123-144). London: Palgrave Macmillan.

Coulthart, S., Landon-Murray, M., \& Van Puyvelde, D. (Eds.). (2019). Researching National Security Intelligence: Multidisciplinary approaches. Washington, DC: Georgetown University Press.

Davids, K. C., Rietjens, S. J. H., \& Soeters, J. M. M. L. (2011). Analysing the outputs of reconstruction efforts in Afghanistan. Journal for Peacebuilding and Development, 6(2), 15-29.

Donkersloot, E., Rietjens, S. J. H., \& Klep, C. (2011). Going Dutch: Counter narcotics activities in the Afghan Province of Uruzgan. Military Review, 91, 44-51.

Dorn, A. W. (2009). Intelligence-led peacekeeping: The United Nations stabilization mission in Haiti (MINUSTAH), 2006-07. Intelligence and National Security, 24(6), 805-835.

Farrell, T., Osinga, F., \& Russel, J. (2014). Military adaptation in Afghanistan. Stanford: Stanford University Press.

Flynn, M. T., Pottinger, M., \& Batchelor, P. D. (2010). Fixing Intell: A blueprint for making intelligence relevant in Afghanistan. Washington, DC: Center for a New American Security.

Galster, K. H. (2015). The face of the foe: Pitfalls and perspectives of military intelligence. Kingston: Legacy Books Press.

Gentry, J. A. (2019). Intelligence in war: How important is it? How do we know?. Intelligence and National Security, 34(6), 833-850.

Gentry, J. A. (2010). Intelligence learning and adaptation: Lessons from counterinsurgency wars. Intelligence and National Security, 25(1), 50-75.

Glass, R. R., \& Davidson, P. B. (1952). Intelligence is for commanders. Harrisburg: Military Service Publishing Company.

Handel, M. (Ed.). (1990). Intelligence and military operations. Abingdon: Routledge.

Hassner, R. E. (2019). What do we know about interrogational torture? International Journal of Intelligence and CounterIntelligence. Online first: https://doi.org/10.1080/08850607.2019. 1660951.

Heuer, R. J., Jr., \& Pherson, R. H. (2011). Structured analytic techniques for intelligence analysis. Washington, DC: CQ Press.

Hulnick, A. S. (2006). What's wrong with the intelligence cycle. Intelligence and National Security, 21(6), 959-979.

Johnson, L. K. (2010). National Security Intelligence. In L. K. Johnson (Ed.), The Oxford handbook of National Security Intelligence (pp. 3-32). Oxford: Oxford University Press.

Johnson, L. K. (2014). The development of intelligence studies. In R. Dover, M. S. Goodman, \& C. Hillebrand (Eds.), Routledge companion to intelligence studies (pp. 3-22). Abingdon: Routledge.

Johnston, R. (2005). The culture of analytic tradecraft. An ethnography of the intelligence community. Washington, D.C.: Center for the Study of Intelligence, Central Intelligence Agency.

Kaldor, M. (2012). New and old wars: Organized violence in a global area (3rd ed.). Stanford: Stanford University Press.

Keegan, J. (2003). Intelligence in war: Knowledge of the enemy from Napoleon to Al-Qaeda. New York: Knopf.

Kitzen, M. W. M. (2012). Close encounters of the tribal kind: The implementation of cooption as a tool for de-escalation of conflict; the case of the Netherlands in Afghanistan's Uruzgan province. Journal of Strategic Studies, 35(5), 713-734.

Koops, J. A., Macqueen, N., Tardy, T., \& Williams, P. D. (Eds.). (2015). The Oxford handbook of United Nations peacekeeping operations. Oxford: Oxford University Press.

Lowenthal, M. M. (2010). The policymaker-intelligence relationship. In L. K. Johnson (Ed.), The Oxford handbook of National Security Intelligence (pp. 437-451). Oxford: Oxford University Press.

Lowenthal, M. M. (2017). Intelligence: From secrets to policy (7th ed.). London: Sage. 
Lowenthal, M. M., \& Clark, R. M. (2016). The 5 disciplines of intelligence collection. Los Angeles: Sage.

Marrin, S. (2012). Is intelligence analysis an art or a science? International Journal of Intelligence and CounterIntelligence, 25(3), 529-545.

Marrin, S. (2017). Why strategic intelligence analysis has limited influence on American foreign policy. Intelligence and National Security, 32(6), 725-742.

Norheim-Martinsen, P. M., \& Ravndal, J. A. (2011). Towards intelligence-driven peace operations? The evolution of UN and EU Intelligence structures. International Peacekeeping, 18(4), 454-467.

Odom, W. E. (2008). Intelligence analysis. Intelligence and National Security, 23(3), 316-332.

Omand, D. (2014). The cycle of intelligence. In R. Dover, M. Goodman, \& C. Hillebrand (Eds.), Routledge companion to intelligence studies (pp. 59-70). Abingdon: Routledge.

Otte, P. (2015). Grayisms and other thoughts on leadership from General Al Gray, USMC (Retired) 29th commandant of the marine corps. Arlington: Potomac Institute Press.

Perugini, N. (2008). Anthropologists at war: Ethnographic intelligence and counter-insurgency in Iraq and Afghanistan. International Political Anthropology, 1(2), 213-227.

Phythian, M. (Ed.). (2014). Understanding the intelligence cycle. London: Routledge.

Rietjens, S. J. H. (2019). Explaining the cultures of intelligence. International Journal of Intelligence and CounterIntelligence, 32(1), 202-207.

Rietjens, S. J. H. (2020). Intelligence in defence organizations: A tour de force. Intelligence and National Security, 35(5), 717-733.

Rietjens, S. J. H., \& Baudet, F. H. (2017). Stovepiping within multinational military operations: The case of Mali. In I. Goldenberg, J. M. M. L. Soeters, \& W. H. Dean (Eds.), Information sharing in military operations (pp. 201-220). Berlin: Springer.

Rietjens, S. J. H., \& de Waard, E. (2017). UN peacekeeping intelligence: The ASIFU experiment. International Journal of Intelligence and Counterintelligence, 30(4), 532-556.

Rittel, H. W., \& Webber, M. M. (1973). Dilemmas in a general theory of planning. Policy Sciences, $4(2), 155-169$.

Ruffa, C., \& Soeters, J. M. M. L. (2014). Cross-National Research in the military: Comparing operational styles. In J. M. M. L. Soeters, P. M. Shields, \& S. J. H. Rietjens (Eds.), Routledge handbook of research methods in military studies (pp. 216-227). Abingdon: Routledge.

Rumsfeld, D. (2002). Press conference by US secretary of Defence, Donald Rumsfeld. Brussels: NATO HQ. Available at: https://www.nato.int/docu/speech/2002/s020606g.htm.

Selmeski, B. R. (2007). Military cross-cultural competence: Core concepts and individual development (Royal Military College of Canada Centre for Security, Armed Forces \& Society Occasional Paper Series). Kingston: Centre for Security, Armed Forces \& Society, Royal Military College of Canada.

Shultz, R. (2018). Post-9/11 wartime intelligence analysis. Intelligence and National Security, 33(7), 974-998.

Steury, D. P. (Ed.). (1994). Sherman Kent and the Board of National Estimates: Collected essays. Washington, DC: CIA.

The Guardian. (2010). The McChrystal Afghanistan PowerPoint slide: Can you do any better? Datablog posted on April 29, 2010. See https:/www.theguardian.com/news/datablog/2010/apr/ 29/mcchrystal-afghanistan-powerpoint-slide. Accessed 25 Aug 2020.

Treverton, G. (2007). Risks and riddles: The Soviet Union was a puzzle. Al Qaeda is a mystery. Why we need to know the difference. Smithsonian Magazine, June 2007. Available at: https:// www.smithsonianmag.com/history/risks-and-riddles-154744750/

UK MOD. (2010). Joint doctrine publication 04 understanding. Shrivenham: UK MOD.

UK MOD. (2011). Joint doctrine publication 2-00: Understanding and intelligence support to joint operations. Shrivenham: UK MOD.

US Army. (2019). Army doctrine publication 2.0. Washington, DC: Headquarters Department of the Army. 
Van Dijk, A., \& Soeters, J. M. M. L. (2008). Language matters in the military. In G. Caforio, G. Kümmel, \& B. Purkayastha (Eds.), Armed forces and conflict resolution: Sociological perspectives (pp. 303-325). Bingley: Emerald Group Publishing.

Van Puyvelde, D., \& Curtis, S. (2016). 'Standing on the shoulders of giants': Diversity and scholarship in Intelligence Studies. Intelligence and National Security, 31(7), 1040-1054.

Von Clausewitz, C. (1984). On war (M. Howard \& P. Paret, Trans. and Ed.). Princeton: Princeton University Press.

Waltz, E. (2014). Quantitative intelligence analysis: Applied analytics models, simulations and games. London: Rowman \& Littlefield.

Williams, H. J., \& Blum, I. (2018). Defining second generation Open Source Intelligence (OSINT) for the Defense Enterprise. Santa Monica: Rand Corporation.

Wolfberg, A. (2017). When generals consume intelligence: The problems that arise and how they solve them. Intelligence and National Security, 32(4), 460-478.

Open Access This chapter is licensed under the terms of the Creative Commons Attribution 4.0 International License (http://creativecommons.org/licenses/by/4.0/), which permits use, sharing, adaptation, distribution and reproduction in any medium or format, as long as you give appropriate credit to the original author(s) and the source, provide a link to the Creative Commons license and indicate if changes were made.

The images or other third party material in this chapter are included in the chapter's Creative Commons license, unless indicated otherwise in a credit line to the material. If material is not included in the chapter's Creative Commons license and your intended use is not permitted by statutory regulation or exceeds the permitted use, you will need to obtain permission directly from the copyright holder.

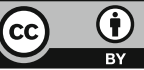

